\title{
Defensa Nacional:
}

\section{consideraciones para un enfoque analítico}

National Defense Policy: considerations for a analytical approach ${ }^{1}$

\author{
Sergio Eissa
}

Resumen: La política de defensa no ha sido una de las prioridades de la sociedad argentina desde el retorno de la democracia. Sin embargo, un conjunto de actores ha "disputado" intensamente sobre qué hacer con las Fuerzas Armadas sin que se hayan puesto de acuerdo al respecto.

El presente artículo se propone no solo indagar sobre los condicionantes que pudieran estar influenciando el debate, sino también se plantea una hoja de ruta para sortear esas trabas que impiden definir los lineamientos para una política de Defensa para el Siglo XXI. A tal efecto se entiende a la Defensa como una política pública y se presenta brevemente un modelo analítico para aprehender la puja en torno a la definición de este issue.

Palabras claves: Argentina; defensa nacional; Glass Onion Model; Fuerzas Armadas

Abstract: Defense policy has not been one of the priorities of Argentine society since the return of democracy. However, a group of actors have "fought" intensely about what to do with the Armed Forces without having agreed on it.

This article proposes not only to investigate the factors that may be influencing the debate, but also to propose a roadmap to overcome those obstacles that inhibiting to define the guidelines for a defense policy for the 21st Century.

For this purpose defense is understood as a public policy and briefly presents an analytical model to apprehend the bid around the definition of this issue.

Key words: Argentina; defensa nacional; Glass Onion Model; Fuerzas Armadas 


\section{Introducción}

La política de Defensa es, junto a la política de Derechos Humanos y la Política Exterior hacia la región, uno de los consensos más importantes alcanzados en la esfera política argentina desde el retorno de la democracia. Sin embargo, no ha sido una de las prioridades de la sociedad argentina desde que la cuestión militar fuera resuelta en el año 1990. Dicho de otra manera, la Defensa Nacional en su "dimensión estratégica" ha sido irrelevante en la agenda pública y gubernamental.

El denominado “Consenso Básico" plasmado en la Ley № 23.554 de Defensa Nacional (1988), la Ley № 24.059 de Seguridad Interior (1992) y la Ley № 25.520 de Inteligencia Nacional (2001 y su modificatoria del 2014) se construye a partir de tres principios liminares: a) la supresión de las hipótesis de conflicto con los países vecinos, b) la conducción civil de la política de Defensa y c) la separación orgánica y funcional de la Defensa Nacional y la Seguridad Interior (Eissa, 2013). Este "Consenso Básico" construido en el ámbito legislativo ha sido disputado intensamente por un núcleo reducido de actores políticos y sociales. La raíz de este debate gira en torno a cuál debería ser la misión principal de las Fuerzas Armadas. Mientras que un grupo sostiene que la expresión "agresión externa", establecida en la Ley de Defensa Nacional, debería ser interpretada en un sentido amplio; otro conjunto de actores restringe la definición a aquellas amenazas estatales militares externas, dejando fuera del ámbito de la Defensa Nacional a las Nuevas Amenazas, o más precisamente, al narcotráfico y el terrorismo internacional. Así esta puja intensa, restringida a este grupo reducido de actores, con algunas breves apariciones en el escenario público, en torno a la definición de qué es la Defensa Nacional ha obturado la posibilidad de tomar acciones que se traduzcan en el plano estratégico militar y logístico del Instrumento Militar con miras al Siglo XXI.

Este artículo se propone empezar a bucear sobre el porqué de esta última cuestión. Para ello, repasaremos brevemente algunas nociones introductorias del Modelo Glass Onion (Eissa, 2015). En segundo lugar, sostenemos que la indefinición en materia estratégica de la Defensa es consecuencia de la irrelevancia de la Defensa Nacional en la agenda pública y en la agenda gubernamental y de un clivaje de pensamiento en el que predominan la matriz realista y la dependiente. Finalmente, se esboza una agenda de investigación y de praxis política para continuar debatiendo esta problemática.

\section{Pensar la Defensa}

La política de Defensa sufre el síndrome de abandono en el ámbito académico de la República Argentina. Así, por ejemplo, no figuraba como sub área temática dentro del Congreso Nacional de Ciencia Política de la República Argentina y, en consecuencia, aquellos que trabajan este tema debían presentar sus ponencias con la incertidumbre de no saber si quedarían englobados dentro del subtópico de "Seguridad Internacional", dentro del campo de las "Relaciones Internacionales", o en "otros" dentro del campo "Estado, Administración y Políticas Públicas". De la misma manera, las Universidades, salvo contadas excepciones, tienen incorporada en la currícula de Ciencia Política o Relaciones Internacionales, la Defensa Nacional, ya sea como materia, seminario o como contenido. 
Este abandono obedece no solo a la irrelevancia que tiene la Defensa Nacional en la agenda pública y gubernamental, sino a que el estudio de la misma requiere un enfoque multidisciplinar. En efecto, tanto la ciencia política, las relaciones internacionales, la historia, la economía y aún, la ingeniería, tienen mucho que aportar al estudio de la política de Defensa. De ahí la importancia de "trasvasar" las fronteras disciplinarias para el análisis de la Defensa Nacional (Ingram \& Fiederlein, 1988; Zahariadis, 2003 y Keohane citado por Llenderrozas, 2013).

Por lo expuesto, hemos empezado a construir un enfoque analítico, que he denominado Glass Onion (Eissa, 2015), a partir del herramental analítico de las teorías de las políticas públicas y de las relaciones internacionales.

\section{3. ¿Qué es la Defensa?}

La Defensa Nacional es el conjunto de acciones que adoptan los Estados para garantizar su supervivencia frente a riesgos y amenazas (Battaglino citado por Eissa, 2015). Asimismo, podíamos dividir la política de Defensa Nacional en tres dimensiones analíticas (Eissa, 2015). En primer lugar, la política militar $^{2}$ que es el conjunto de decisiones orientadas a regular el comportamiento político que, generalmente, tienden a desarrollar las Fuerzas Armadas. Esta dimensión se encuentra fuertemente dirigida a alcanzar el control civil.

En segundo lugar, la dimensión estratégica que puede ser definida como las acciones, actitudes y medidas estratégicas destinadas a prevenir o enfrentar distintas situaciones de riesgo, conflicto o amenazas, potenciales o reales, que hagan peligrar los intereses vitales y estratégicos de un país y que requieran el empleo del Instrumento Militar. Esta dimensión se relaciona con la conducción político-civil de la Defensa Nacional.

En tercer lugar, la dimensión internacional que es aquella que contribuye a la Política Exterior y que es definida como la política internacional de la Defensa. Esta última dimensión es la que debería permitir la articulación entre la Política de Defensa y la Política Exterior, al menos de dos maneras. En primer lugar, aquella contribuye a la Política de Defensa a través de lo que los militares denominan la maniobra diplomática. En segundo lugar, la Política de Defensa resulta fundamental para la Política Exterior porque en un escenario de incertidumbre estratégica, donde no queda clara quién o qué es la amenaza, ni su magnitud ni su intención y dirección, amortigua (no suprime) los riesgos de la adopción de una determinada actitud y posicionamiento estratégico. Asimismo, la Política de Defensa es fundamental para hacer creíble la Política Exterior. Son sus dientes, que no se quieren mostrar, pero que están ahí cuando resultan necesarios (Eissa, 2017).

La relación entre ambas no termina aquí. La Política Exterior precede a la Política de Defensa. En efecto, siguiendo a Carl von Clausewitz, consideramos que la guerra es un hecho social, pero fundamentalmente político. En consecuencia, como sostenía Raymond Aron, la guerra surge de la política, determina su intensidad, le define el motivo y le fija sus objetivos políticos (Eissa, 2015). La guerra termina cuando se alcanzan los objetivos políticos o, mejor aún, cuando la política dice que se alcanzaron sus objetivos. Los objetivos de la guerra no son militares. Los objetivos estratégicos militares están en función de

2 Henri de Jomini (1991) ya hacía mención a esta dimensión a principios del Siglo XIX. 
los objetivos políticos. Si no existen objetivos políticos no hay guerra. Es esto último lo que diferencia a los actores políticos de las organizaciones criminales (Aron, 1987). ${ }^{3}$

Por ello, Clausewitz sostenía brillantemente que

A partir de esta concepción, hay que considerar ilegítima e incluso nociva la distinción según la cual un gran acontecimiento militar o el plan de semejante acontecimiento debería permitir un juicio estrictamente militar; en verdad, consultar a los militares con respecto a los planes de guerra para que ellos den un juicio puramente militar [...], es un procedimiento absurdo; pero mucho más absurdo es el criterio de los teóricos según el cual los medios de guerra disponibles deberían confiarse al jefe militar para que en función de estos medios él establezca un proyecto puramente militar de la guerra (Clausewitz, 1976: 325)

\section{4. ¿Qué es la Defensa? Reprise}

La Política de Defensa es una Política Pública que al igual que la Política Exterior se despliega en el escenario internacional frente a otros actores políticos. En consecuencia, y a los fines de esta ponencia, desarrollamos muy esquemáticamente algunos aspectos del Modelo Glass Onion (Eissa, 2015).

\section{Primera Parte}

El proceso de política pública es una construcción analítica. No es algo que podamos encontrar en la realidad, donde más bien es desordenado, en el que se mezclan y sobreponen las distintas etapas, pero que nos sirve como "instrumento" para estudiar las decisiones que se adoptan en torno a un problema público (Aguilar Villanueva, 1993; Sabatier, 2007)

La primera etapa del proceso sería el reconocimiento del problema, pero en este punto debemos distinguir entre problemas y situaciones problemáticas. Mientras que la situación problemática es un conjunto de "hechos vividos u observados por el sujeto y que al ser referidos a su cuadro valorativo arrojan conclusiones negativas de reprobación y malestar"; los problemas son construcciones lógicas que estructuramos de tal manera que tengan una respuesta, es decir, que la solución sea parte de la definición del mismo (Aguilar Villanueva, 1993: 58 y 61).

Ahora bien, una situación problemática para entrar en la agenda pública debe transformarse en un problema, para lo cual el mismo debe ser objeto de debate en la sociedad en lo que respecta a sus componentes, causas, consecuencias y planteamiento, acerca de cómo puede ser resuelto y en cuánto si requiere algún tipo de acción por parte de una agencia estatal. De esta manera, será importante, en un primer momento, el contexto en el cual se desarrolla el debate, porque son los acontecimientos y actores

\footnotetext{
3 “Digamos, en términos abstractos, que Clausewitz, Marx, Lenin y Mao concuerdan en enseñarnos que las guerras solo adquieren sentido a la luz de la política, en los dos sentidos de la palabra: la coyuntura de donde surge la guerra, la intención de los combatientes (...) Olviden que un terrorista sin causa se parece a un salteador de caminos" (Aron, 1987: 144 y 158).
} 
políticos y sociales quienes se encargan de convertirlos las situaciones problemáticas en problemas y ofrecer su primera definición (Aguilar Villanueva, 1993).

En este punto, debemos distinguir dos tipos de agenda. La primera es llamada pública y que "está integrada por todas las cuestiones que los miembros de la comunidad política perciben comúnmente como merecedoras de la atención pública". En cambio, la agenda gubernamental es "el conjunto de asuntos explícitamente aceptados para consideración seria y activa por parte de los encargados de tomar las decisiones" (Aguilar Villanueva, 1993: 31-32).

Sin embargo, que un problema haya ingresado en la agenda pública no supone que ingrese automáticamente en la agenda gubernamental y, menos aún, que se le dé un tratamiento prioritario, porque el gobierno no sólo regula y actúa como filtro de esos problemas, sino que también puede ser iniciador de cuestiones en la agenda pública (Aguilar Villanueva, 1993: 53).

De esta manera, cuando un problema ingresa en la agenda gubernamental es nuevamente debatido y definido, entendiendo la definición del problema como el proceso por el cual una cuestión "es estudiada, explorada, organizada y posiblemente cuantificada por los interesados"; esa definición condicionará "la configuración de los instrumentos, modos y objetivos de la decisión pública, las opciones de acción" (Aguilar Villanueva, 1993: 52). Por lo tanto, existirá una interdependencia conceptual entre la definición y la solución, porque "la solución forma parte de la misma definición del problema" (Aguilar Villanueva, 1993: 60); es decir, que "la definición del problema no puede ser tratada como un proceso separado, sino como parte integral de la hechura de la política" (Zahariadis, 2003: 162).

En otras palabras, la forma en que se define un problema condiciona la selección de los instrumentos, modos y objetivos de la política pública, es decir, las opciones de acción o, dicho de otra manera, las alternativas de políticas disponibles para el decisor (Aguilar Villanueva, 1993; Eissa, 2006: 13; Eissa, 2005: 22). Dentro de ese conjunto de alternativas, ya limitadas por la manera en que ha sido problematizado el problema, la decisión estará condicionada por los actores y organismos involucrados en el proceso, las variables que el decisor pueda manipular, la relevancia del problema, la calidad y la cantidad de la información, y la personalidad del decisor (Mena, 1989 y Eissa, 2005: 23).

Por ello, puede suceder también, que los problemas no puedan ser bien definidos hasta que las soluciones estén disponibles. Dado el contexto de incertidumbre y de ambigüedad, que resulta en una asimetría de información, algunos actores podrán influenciar el proceso para ajustar la definición a la solución deseada. La clave está en cómo se presenta la información al decisor (Zahariadis, 2003). En palabras de Aguilar Villanueva (1993: 52), "quien define es quien decide".

Por lo expuesto, el estudio de la formación de la agenda de gobierno y las decisiones allí adoptadas nos permiten saber quiénes definen y deciden; qué grupos y organizaciones han influido en el proceso; y "cuál es el firmamento ideológico que otorga valor y prioridad a un problema público". Este análisis revela "cuál es la estructura de poder" que predomina en la hechura de la Política Pública (Aguilar Villanueva, 1993: 27).

Esta puja por la definición continua durante todo el proceso de Política Pública, incluso durante la implementación, donde los actores políticos, opuestos a la definición del problema, tratarán de trabarla o cambiar el sentido de su definición. 


\section{Segunda Parte}

Como ya hemos dicho, el actor estatal "tiene la posibilidad de ejercer un poder público en función de que, en última instancia, las políticas públicas son fijadas e implementadas por el Estado" (Repetto, 1998: 10-11). Pero ese Estado no es un actor racional unificado, dado que existen no sólo diferentes agencias que compiten entre sí, sino también que la competencia se desarrolla dentro de las mismas y entre los actores políticos de unas con otras. Entonces, cuando nos referimos al actor estatal no estamos pensando en un Estado monolítico que actúa racionalmente, dada la complejidad de elementos que lo forman, las relaciones que se establecen con la sociedad, las distintas percepciones que se establecen entre ellos y las distintas capacidades de influenciarse mutuamente. Por otra parte, si bien en el proceso de toma de decisión intervienen actores sociales y estatales, articulados en un complejo mecanismo social de interacciones e influencias mutuas, en el caso de la Política Exterior y de Defensa, la decisión final y la implementación, quedará a cargo del actor estatal ${ }^{4}$.

En efecto, si se desea saber y explicar las preferencias de un Estado con relación a las estrategias que desarrolla, es necesario saber quiénes tienen poder, qué desean, y qué creen. Para ello, debemos ver al Estado como el conjunto de individuos, en el cual, los líderes políticos y los burócratas son individuos que intentan maximizar el éxito de sus carreras (Geddes, 1994: 13). Entonces, las decisiones que tomen en materia de Políticas Públicas reflejarán sus intereses. Ahora bien, esos actores actúan dentro de determinados "marcos contextuales", que influyen en sus incentivos (Geddes, 1994 y Putnam, 1988 y 1993).

Asimismo, Robert Jervis sostiene que es imposible explicar las políticas y decisiones cruciales sin referencia a las creencias de los decisores sobre el mundo y sus imágenes sobre los otros (Dos Santos Ferreira, 2006) ${ }^{5}$. Por otro lado, eventos previos en el escenario internacional ayudarán al decisor a construir percepciones para comprender el mundo y actuar frente a un nuevo evento.

En síntesis, influyen en las decisiones de los actores sus creencias individuales, sus imágenes, sus valores, sus capacidades, sus actitudes, sus talentos y experiencias previas (Russell, 1991) y sus intereses (Geddes, 1994).

El proceso de hechura de la política no sólo se produce en un marco de incertidumbre, en el cual los actores toman decisiones sin conocer la totalidad de la información, sino también que esa elección no es necesariamente racional y que, además, se produce en un contexto de ambigüedad. Según este autor, la ambigüedad es central, y "la manipulación es la lucha" [por controlarla] (Zahariadis, 2003: 18).

En efecto, la conceptualización de un problema implica no sólo que determinados elementos del mismo serán tenidos en cuenta en detrimento de otros, sino que también la forma en que se ha definido implicará la asignación de responsabilidades y de recursos

4 Para Fabián Reppeto (1998: 10-11), los actores sociales y estatales poseen cinco características comunes: a) capacidad de negociación, b) capacidad de descifrar el contexto, c) capacidad de representación, d) capacidad de movilización social, y e) capacidad de acción colectiva. Sin embargo, el actor estatal está en condición de "movilizar un recurso que le es propio: capacidad de autoridad"; es decir, "[la] posibilidad de ejercer el poder público en función de que, en última instancia, las políticas son fijadas e implementadas por el Estado". Ver también, Robert Putnam (1988: 432-433) y Roberto Russell (1990: 12).

5 Ver también Corigliano (2008: 8). 
presupuestarios al interior del Estado. En la lucha por definir un problema de una manera u otra intervendrán los actores, con distintos recursos de poder y de información. Aquellos que tengan ventaja debido a la asimetría de información podrán manipular a los decisores e influenciar en la agenda de acuerdo con sus intereses y/o sistemas de creencias (Zahariadis, 2003). Estos actores son los denominados "emprendedores políticos" (entrepreneurs). A los fines de este modelo, cualquier actor podrá ser un entrepreneur que, por el tema que se esté tratando, tenga interés en el mismo y que, debido a su ventaja en el manejo de la información -porque sabe lo que quiere-, tenga poder para manipular a los decisores: esto supone tener la capacidad de presentar una propuesta de política, de modificarla, o de bloquearla. Previamente no podremos establecer, entonces, quiénes serán esos emprendedores políticos, como asimismo, tampoco podremos saber quiénes serán los actores que intervengan en un proceso de hechura de una política pública. Pero debe quedar claro, por lo expuesto más arriba, que estos actores "especiales" pueden ser tanto domésticos como externos (Zahariadis, 2003).

La implementación de una política pública requiere de la convergencia de intereses y sistemas de creencias de actores interesados en la temática con más capacidad de poder de los que se oponen a cómo ha sido definida la misma.

\section{Tercera Parte}

Ahora bien, hemos visto que los actores toman decisiones dentro de determinados marcos contextuales, es decir, que están influidas por un conjunto de factores contextuales ${ }^{6}$. A los efectos de nuestro modelo, los factores que moldean esas decisiones pueden ser clasificados en ${ }^{7}$ :

a) Sistémicos, entendidos como todos los factores externos que influyen en la toma decisión; es decir, cambios en la estructura internacional, en los regímenes internacionales, cambios sociales y tecnológicos globales, como así también las ideas;

b) Institucionales, es decir instituciones, prácticas institucionales y todos los aspectos de la estructura gubernamental que limitan o fortalecen las elecciones que realizan los actores;

c) Sociales, es decir:

i) dimensión socio cultural histórica: las ideas, "las interpretaciones y mitos históricos permean las percepciones de los actores políticos [...]. Estos han sido cruciales en la generación de los sistemas de creencias, las imágenes y los prismas actitudinales de las élites de política exterior" (Van Klaveren, 1992: 198; Femenia, 2000). Además, es relevante la "cultura política", entendida como la manera en que la gente piensa acerca de la política y cómo se comporta en política.

ii) dimensión socioeconómica: han tenido especial incidencia en la política exterior de Latinoamérica (Van Klaveren, 1992).

6 Ver también Tini (2005: 104).

7 Ver entre otros a Rosenau (1966), Tomassini (1989); Russell (1990 y 1991) y Van Klaveren, (1992). No estamos siguiendo exactamente la clasificación que, con algunas diferencias, hacen estos autores. Russell hace mención a las variables de rol que hace que determinados actores en un mismo rol, se comporten de igual manera, independientemente de sus características personales. Preferimos usar el término factores antes que variables, porque este último concepto puede prestarse a confusiones. 
iii) dimensión sociodemográfica: se refiere a la naturaleza y composición de la población, así como a su estructura social.d) Sistema político:

i) dimensión régimen político: hace referencia a la relación entre política exterior y la forma de organización política (básicamente democrática o autoritaria). Como señala Van Klaveren (1992), esta relación ha sido ampliamente estudiada en América Latina a través de estudios diacrónicos. Los resultados, si bien no permiten establecer una generalización acerca del impacto de un tipo de régimen en la Política Exterior (agresiva, activa, etc.), no dan lugar a duda sobre su influencia en ella;

ii) dimensión dinámica política: se refiere a la dinámica política, la relación entre el Poder Ejecutivo y el Congreso, al peso y frecuencia de las elecciones, al rol de la oposición, y la relación entre el gobierno federal y las provincias.

En resumen, los actores tomarán las decisiones de acuerdo con sus intereses y sus sistemas de creencias. Dichas decisiones se adoptan en un contexto de incertidumbre y ambigüedad, lo cual permite que ciertos actores - emprendedores políticos - tengan la capacidad para que determinada cuestión se problematice en función de sus intereses. Pero las decisiones que adoptan los actores o los intentos de algunos de ellos de influir a lo largo del proceso, desde la problematización y hasta la implementación, estarán influida por un conjunto de factores.

\section{El debate}

No es el propósito del artículo analizar todos los condicionantes del proceso de política pública de la política de Defensa, tema que ya he abordado en un trabajo previo (Eissa, 2015). En este punto más que indagar sobre los por qué las variaciones en la toma de decisiones entre 1983 y 2015, nos preguntamos sobre el por qué de una constante a lo largo de todos esos años: la irrelevancia de la política de Defensa Nacional y la constante puja en torno a la "definición" sobre qué es Defensa Nacional.

Por un lado, tanto las encuestas de opinión ${ }^{8}$ como la asignación de recursos presupuestarios $^{9}$ (Eissa, 2015), muestran que la Política de Defensa no ha formado parte de la agenda pública ni de la agenda de gobierno, o dicho de otra manera, tanto la sociedad civil como los actores políticos no se han mostrado interesados en ella. Sin embargo, como hemos sostenido ut supra, el debate ha sido intenso entre un grupo reducido de actores y, desde el año 1990, el mismo ha girado en torno a la definición de "Defensa Nacional” ${ }^{\prime 10}$. Tal como se expuso en el apartado previo, esta discusión no es inocua por-

8 En cuanto a las encuestas de opinión ver Mora y Araujo (2010), IPSOS-FLACSO (2010) y CARI (1998, 2002, 2006 y 2010). Es interesante señalar que aún, en las encuestas realizadas por el CARI entre los líderes de opinión se refleja tanto la irrelevancia como la puja del debate reseñada por diversos autores (ver cita 11).

9 Ver también Ernesto López (1994), Miguel Pesce et al (1999).

10 Sobre el debate en los años ochenta sugerimos la lectura de Ernesto López (1994), Marcela Donadio (2000), Patrice McSherry (2008), Horacio Verbitsky (1987), Gustavo Druetta (1989), Herbert Huser (2002) y Sergio Eissa (2015). En cuanto a los años noventa y 2000 se sugiere a Marcelo Saín (1997), Patrice McSherry (2008), Herbet Huser (2002), Marcelo Saín (2003), José Manuel Ugarte (2003), David Pion-Berlin (2005), Guido Braslavsky (2009), Paula Canelo (2010) y Sergio Eissa (2015). La lista no es exhaustiva. 
que refleja la estructura de poder en torno al issue y, en consecuencia, los intereses y el sistema de creencia de los actores que intervienen en este proceso. La respuesta se halla parcialmente en la dimensión socio cultural histórica: el legado del pasado. Ese legado del pasado, que se proyecta como una sombra sobre la actualidad, es como un "espejo retrovisor" que toma distintas formas: a) el rol de las Fuerzas Armadas en la vida política argentina: sus intervenciones en el sistema político, el terrorismo de Estado y el fracaso en la Guerra de Malvinas; b) la hipótesis de conflicto con Chile y Brasil; y c) la agenda de Estados Unidos de las Nuevas Amenazas para con la región. Estas tres sombras son un legado histórico que aún pesa en la agenda pública y de gobierno (Eissa, 2015). Sin embargo, esta no es la única explicación y sobre eso queremos proponer una ruta de investigación en los siguientes apartados.

Por otro lado, y sin embargo, los académicos y especialistas ${ }^{11}$ en esta temática coinciden en un aspecto, que conforman el núcleo duro de debate que hemos señalado a lo largo del artículo, disienten en otros dos y parcialmente están de acuerdo en uno. Empecemos por este último.

En primer lugar, concuerdan en que el actual escenario internacional es incierto, que no existe una amenaza clara y presente que afecte los intereses vitales y objetivos de valor estratégico de nuestro país. Las guerras del futuro estarán probablemente asociadas a la disputa de los recursos naturales estratégicos, entre los cuáles el Atlántico Sur y la Antártida cobran una vital relevancia, y serán de corta duración con un uso intensivo de la tecnología, donde resultará clave obtener una ventaja relativa hasta la intervención internacional. Asimismo, se han multiplicado los actores y los problemas, aunque no todos ellos pueden ni deben ser resueltos a través de medios militares. Está claramente demostrado el fracaso de la Guerra contra las Drogas, que el uso de la fuerza (el máximo uso de la fuerza que representan las Fuerzas Armadas) no resuelve el aumento del consumo de drogas ni los delitos conexos con el narcotráfico. De la misma manera, tampoco éstas son eficaces para luchar contra el delito complejo o delito transnacional o las mal llamadas "Nuevas Amenazas"12, si entendemos por las mismas al narcotráfico, el tráfico

11 Estos académicos y especialistas conforman una comunidad epistémica. De acuerdo a Haas (1992), ésta se evidencia cuando "las interpretaciones compartidas conducen a un sentido de identificación y solidaridad dentro del grupo", pero así también, éstos conducen a aversiones compartidas. Por su parte, Sabatier (1993) define la coalición de apoyo que son grupos de instituciones públicas y privadas que comparten sistemas de creencias y que "trabajan como una coalición para lograr sus objetivos políticos". Citamos "algunos" autores de esta comunidad epistémica argentina: Acuña et al (2005), Anzelini et al (2017), Bartolomé (2006, 2010 y 2017), Battaglino (2008 y2010), Battaleme (2017), Busso (1999) Canelo (2010), Diamint (1999, 2002, 2004, 2006, 2008 y 2014)), Donadio (1996 y 2000), Druetta (1989), Druetta et al (1990), Eissa (2013, 2015, 2017), Estévez (1990), Fontana (1998), Fraga (1989, 1997, 1998 y 2002), Frederic (2013), Frederic et al (2010), Fundación Arturo Illia (1986, 1988), García et al (1987), Gastaldi (2012), Hirst (1996 y 2004), López (1994 y 2007), Llenderrozas (2007), Martínez (2000 y 2002), Montenegro (2003, 2006 y 2013), Orieta (1985), Pesce et al (1999), Poczynok (2012), Saín (1997, 2000, 2003, 2007 y 2010), Scheetz (1993, 1994, 1995 y 2015), Soprano et al (2015), Soprano (2016), Tello (1998, 1999, 2001, 2004, 2006), Tibiletti et al (1997), Tokatlian (2004, 2007, 2015, 2016 y 2017), Ugarte (1990, 2003 y 2011), Vigliero (2002, 2004 y 2005).

12 Entendemos por Nuevas Amenazas aquellas "cuestiones", nuevos o viejos, que han sido socialmente problematizadas, de manera tal que, en términos de la Escuela de Copenhague, fueron securitizadas y, por lo tanto, ingresados en la agenda de defensa nacional. La securitización de estas cuestiones está asociada a cómo los mismos son definidos, la cual no es neutral ni objetiva sino que responde a los intereses y sistemas de creencias de los actores políticos y sociales, domésticos y externos, involucrados en la definición (Eissa, 2015). 
de personas, tráfico de armas, entre otras. Es más, tampoco son eficaces para prevenir un ataque terrorista. Más inteligencia estratégica criminal y una agencia federal de investigaciones son más útiles que un tanque, un avión y un destructor.

En segundo lugar, se coincide ampliamente en que hay que recuperar las capacidades militares de las Fuerzas Armadas. No hay duda al respecto. Un país mediano como Argentina no puede darse el lujo, ni el peligro futuro, de no contar con Fuerzas Armadas. La Defensa Nacional es como un seguro de vida o cómo una obra social. Es algo que jamás querremos usar, pero que hay que tener por las dudas. Es más, una Política de Defensa exitosa es aquella que nunca desemboca en una guerra. Las Fuerzas Armadas son, en términos weberianos, la materialización del monopolio legítimo de la coerción.

El tercer lugar, no se coincide en el para qué y en el cómo. Si de acuerdo a nuestro modelo la definición sesga las alternativas de políticas públicas, claramente existe una fuerte divergencia dentro de este núcleo duro de especialistas en cuanto al sistema de creencias a partir del cual se aborda la problemática de la defensa nacional. Nuestra hipótesis es que dos variables inciden en esa construcción de ideas: el pensamiento estratégico dependiente y el peso de la escuela realista en la Defensa Nacional. ${ }^{13}$

Existiría en nuestro país en algunos medios, ámbitos académicos y políticos una suerte de pensamiento estratégico "dependiente y/o resignado". Adoptan la agenda de otros países, que responden a los intereses de esos países, para definir la misión de las Fuerzas Armadas y/o caen en la desesperación de adoptar esa agenda para aumentar el presupuesto y acceder a equipamiento. Esa agenda no es necesariamente la de Argentina. Nuestra política de Defensa debe estar en consonancia con nuestros intereses vitales y estratégicos. La resignación resulta de las presiones de la agenda de Seguridad hacia la de Defensa. La población y los líderes de opinión consideran que los principales problemas provienen del delito organizado, del narcotráfico y del terrorismo, en consecuencia, si esos son los temas de agenda pública, la definición de los decisores estará sesgada a dirigir los recursos hacia el Ministerio de Seguridad y las Fuerzas de Seguridad. Muchos militares genuinamente creen qué apropiándose de esos temas, redefiniendo la Defensa, lograrían una mayor asignación de recursos para el sector.

Asimismo, también existe un pensamiento realista "nostálgico" que quiere reactivar las hipótesis de conflicto con los países de la región. En algunos casos porque están convencidos que los países no pueden ser socios estratégicos y que sólo pueden confiar en sus propias capacidades militares para salvaguardar sus intereses. Esta línea de pensamiento también se ve atravesada por la necesidad de justificar un aumento del presupuesto de Defensa Nacional.

Por último, existe una especie de liberalismo "ingenuo" que cree que el libre comercio y los organismos internacionales vuelven innecesarias las Fuerzas Armadas y que, por lo tanto, quieren convertirlas en una especie de Gendarmería y Prefectura reloaded y algunos, aunque no lo dirían jamás en público, estarían encantados en no tener que lidiar con ellas.

¿Cuál sería el cuarto cuadrante? Sigamos al siguiente apartado. 


\section{Reflexión final: La agenda de investigación y de la praxis}

\section{Investigación}

La ausencia de amenaza (clear and present danger), entendida como construcción social, no termina de explicar la falta de definiciones en materia de Política de Defensa. Tal como reflejan las encuestas del Centro Argentino de Relaciones Internacionales (CA$\mathrm{RI})$, el narcotráfico y el terrorismo son percibidos como las principales amenazas para la Seguridad Nacional por los líderes de opinión (entrepreneurs). Entonces, ¿por qué sucede esto, por qué cíclicamente se reflotan las hipótesis de conflicto con los países de la región y las Nuevas Amenazas, particularmente el narcotráfico y el terrorismo islámico como hipótesis de empleo de las Fuerzas Armadas y no se construye una amenaza estatal militar externa? Una primera hipótesis es que esto es producto del entrecruzamiento de dos variables: a) la prevalencia de un pensamiento estratégico dependiente (que se refleja no solo en la esfera militar) y b) el peso de la escuela realista, forjado en el predominio militar en los debates sobre la teoría de las relaciones internacionales (Colacrai, 1992). Creemos que esta es una línea de investigación que debemos abordar desde la academia más fuertemente: ¿cuál es el sistema de ideas que construye la Defensa Nacional?

La hipótesis de trabajo que sometemos al debate es que la conjunción de estos dos factores "arrastra" permanentemente a la Defensa Nacional al Siglo XX, lo cual se refleja en los tres tópicos del legado del pasado: la cuestión militar, las Nuevas Amenazas como hipótesis de empleo de las Fuerzas Armadas y el resurgimiento de las hipótesis de conflicto con los países de la región. Ese debate intenso se refleja en un espejo retrovisor que va mutando en torno a estos tres ejes sin avanzar nunca sobre una agenda, sin definir, que se encuentre anclada en el Siglo XXI.

Asimismo, resulta relevante estudiar el impacto del factor Sistema Político en el diseño de la Política de Defensa. Nuestra segunda hipótesis es que: 1) "la estructura de incentivos institucionales en la política argentina lleva a que quienes son elegidos para el Congreso no deseen permanecer en él mucho tiempo, sino que prefieran cargos ejecutivos"; 2) "el pasaje rápido por el Congreso y la consecuente alta tasa de renovación de los diputados y senadores hace que no se invierta institucionalmente en el congreso; y 3) "dados 1 y 2, no hay políticas de largo plazo generadas por el congreso", que es justamente lo que requiere la Política de Defensa. Cuando nos referimos a la dinámica política no estamos pensando en el diseño del Sistema Político porque, por ejemplo, esto no tiene que ver con que se realicen elecciones cada dos años, sino que "los políticos argentinos no ven a una banca en el Congreso como un lugar desde donde hacer política a largo plazo (EEUU también tiene elecciones cada dos años y, sin embargo, hay políticas a largo plazo porque los legisladores se quedan en sus bancas ininterrumpidamente durante 20 o 30 años)." ${ }^{14}$

\section{Praxis}

La falta de debate académico sobre qué hacer con las Fuerzas Armadas en el Siglo XXI se refleja obviamente en las alternativas de políticas públicas, particularmente, en la

14 Estas ideas se las debo a Miguel De Luca. 
ausencia de una propuesta acorde a la realidad regional y nacional. Las líneas que siguen pretenden ser una punta para pensar una política de defensa para los años venideros.

Para ello nos preguntamos, ¿son necesarias las Fuerzas Armadas? Por supuesto que sí. ¿Para qué? La política de Defensa Nacional y, particularmente, sus Fuerzas Armadas deben adiestrarse, alistarse y prepararse para conjurar y repeler una agresión militar estatal externa contra los intereses vitales y/o una agresión que afecte los objetivos de valor estratégico, que son aquellos cuya afectación torna inviable la Defensa y al país en sí mismo. Asimismo, deben contribuir a la Política Exterior argentina participando activamente en las operaciones internacionales que la Cancillería argentina defina. Por otro lado, deben estar preparadas también para coadyuvar a otras agencias del Estado en situaciones de desastres antrópicas y/o naturales en nuestro país y/o en países amigos que la requieran. Por último, deben contribuir a la integración regional fortaleciendo los lazos regionales, tal como se ha hecho con la Fuerza de Paz Combinada "Cruz del Sur con Chile y la Compañía de Ingenieros "General San Martín" con Perú.

¿Cómo hacemos esto? En primer lugar, no debemos realizar más modificaciones normativas a las leyes, decretos y resoluciones existentes, redactadas durante tres gobiernos diferentes, y materializados en cuatro leyes: la Ley de Defensa Nacional (1988), la Ley de Seguridad Interior (1992), la Ley de Reestructuración (1998) y la Ley de Inteligencia Nacional (2001 y 2014).

En segundo lugar, la Ley de Defensa Nacional prevé claramente que nuestro Sistema de Defensa puede adoptar hipótesis de conflicto o hipótesis de confluencia. Pero desde el gobierno de Raúl Alfonsín hasta la actualidad, y ésta es una de nuestras políticas de Estado, Argentina no tiene hipótesis de conflicto que requieran la utilización del Instrumento Militar contra los países de la región. Esto no significa, que no necesitemos a las Fuerzas Armadas, sino simplemente que no sabemos quién puede ser un enemigo, más aún en este mundo incierto. Por ello, hay que pasar del análisis del quién al qué: no es relevante "quién" será el enemigo sino con "qué" capacidades militares contaremos para defender nuestros intereses vitales y estratégicos. Para ello se utiliza la metodología de planeamiento por capacidades y no la obsoleta metodología de planeamiento por hipótesis de conflicto. Volviendo a la analogía: no sabemos con certeza qué enfermedades podemos llegar tener, pero si tenemos algunos indicios sobre con qué recursos médicos deberíamos contar para enfrentarlas, lo cual ha cambiado a lo largo del tiempo. No obstante, y no debemos limitarnos en el debate, si bien la Constitución Nacional prohíbe recuperar las Islas Malvinas y las islas del Atlántico Sur por la vía militar, la presencia de las Fuerzas Armadas británicas en nuestras islas también constituye una amenaza al territorio continental y al mar argentino. Esta situación debe estar reflejada en el planeamiento de la defensa nacional.

En tercer lugar, debemos pasar ya a reformas de cuarta generación. Es decir, establecer un sistema de ingreso de profesionales al Ministerio de Defensa a través de la Universidad de la Defensa Nacional, similar al existente en la Cancillería; modificar la Ley de Personal Militar № 19.101; adecuar el despliegue a la actual realidad regional y nacional, dado que el vigente data de la década del '60; definir una estructura orgánica acorde $y$, luego recién, mejorar paulatinamente el presupuesto hasta converger con el 1,5\% del PBI. Incrementar el presupuesto sin hacer esos cuatro cambios sería, por un lado, un despilfarro, pero, por otro lado, sería un mero ejercicio académico si no se mejora el presupuesto. ¿Cómo podemos realizar esta "inversión en defensa"? Una alternativa sería crear un fondo específico para efectuar las inversiones en equipamiento $-\mathrm{y}$ no en gasto 
corriente- que podría ser financiado a través de las retenciones a las exportaciones agrícola-ganadera, minera y petrolera.

Hay que dejar de discutir para atrás, mantener lo que se hizo bien y mirar al futuro porque si prestamos mucha atención al retrovisor podríamos terminar chocando.

\section{Bibliografía}

Acuña, M. y Runza, R. (2005), Hacia la modernización del sistema de defensa argentino. Buenos Aires: Altamira.

Aguilar Villanueva, L. (1993), “Estudio introductorio”, en Aguilar Villanueva, L. (comp.), Problemas Políticos y Agenda de Gobierno, México: Ed. Miguel A. Porrúa, pp. 1572.

Anzelini, L; Poczynok, I. \& Zacarías Di Tullio, E. (2017), Política de defensa y militar en Argentina desde el retorno de la democracia (1983-2015), Serie de Documentos de Trabajo 4, Buenos Aires: UMET.

Aron, Raymond (1987), Pensar la Guerra, Clausewitz. Tomo 1: La Era Europea y Tomo 2: La era planetaria, Buenos Aires: Instituciones de Publicaciones Navales.

Bartolomé, M. (2006), La seguridad internacional en el siglo XXI. Más allá de Westfalia y Clausewitz, Santiago de Chile: Academia Nacional de Estudios Políticos y Estratégicos - Ministerio de Defensa de la República de Chile.

Bartolomé, M. (2017, 21 de julio), “La Defensa Nacional necesita un plan”, en La Nación, Buenos Aires.

Battaglino, J. (2010), “La política militar de Alfonsín: la implementación del control civil en un contexto desfavorable", en Gargarella, R.; Murillo, M. y Pecheny, M. (comps.), Discutir Alfonsín, Buenos Aires: Siglo XXI, pp. 161-184.

Battaglino, J. (2008), “Palabras mortales. ¿Rearme y carrera armamentista en América del Sur?, Nueva Sociedad. Santiago de Chile: Fundación Friedrich Ebert, № 215, pp. 23-34.

Battaleme, J (2017, 12 de junio), "La defensa nacional necesita construir capacidades", en Zona Militar, Buenos Aires.

Braslavsky, G. (2009). Enemigos íntimos. Los militares y Kirchner. De la purga a los juicios. Crónica de una confrontación (2003-2008). Buenos Aires: Sudamericana.

Busso, A. (1999). Las relaciones Argentina-Estados Unidos en los noventa. El caso Cóndor. Rosario: Centro de Estudios en Relaciones Internacionales de Rosario (CERIR).

Canelo, P. (2010). ¿Un nuevo rol para las Fuerzas Armadas? Políticos y militares frente a la protesta social, los derechos humanos y la crisis presupuestaria (1995-2002). Buenos Aires: Consejo Latinoamericano de Ciencias Sociales (CLACSO).

Consejo Argentino para las Relaciones Internacionales (CARI) (1998), La opinión pública argentina sobre política exterior y defensa, Buenos Aires: Consejo Argentino para las Relaciones Internacionales. 
Consejo Argentino para las Relaciones Internacionales (CARI) (2002), La opinión pública argentina sobre política exterior y defensa. Buenos Aires: Consejo Argentino de Relaciones Internacionales.

Consejo Argentino para las Relaciones Internacionales (CARI) (2006), La opinión pública argentina sobre política exterior y defensa. Buenos Aires: Consejo Argentino de Relaciones Internacionales.

Consejo Argentino para las Relaciones Internacionales (CARI) (2010), La opinión pública argentina sobre política exterior y defensa. Buenos Aires: Consejo Argentino de Relaciones Internacionales.

Corigliano, F., "Híbridos teóricos y su impacto en la política exterior: el caso de los gobiernos de Néstor y Cristina Kirchner", Boletín Instituto de Seguridad Internacional y Asuntos Estratégicos (ISIAE), Buenos Aires: Instituto de Seguridad Internacional y Asuntos Estratégicos - Consejo Argentino para las Relaciones Internacionales, Año 11, № 47, 2008, pp. 8-10.

Donadio, M. (2000), De los golpes a la colaboración. Una mirada a la mentalidad profesional en el Ejército Argentino. Tesis de Maestría, Facultad Latinoamericana de Ciencias Sociales (FLACSO), Buenos Aires. Disponible en: www.resdal.org/Archivo/mar-5.htm.

Donadio, M. (1996) “La construcción de una nueva política de defensa en Argentina", Revista Fuerzas Armadas y Sociedad (FASOC). Santiago de Chile: FLACSO, Año 11, № 2,pp. 3-8.

Dos Santos Ferreira, M. (2006), O impacto da política externa dos EUA nas relaçoes entre Brasil e Cuba (1996-2004). Tesis de Maestría, UNESP/UNICAMP/PUC-SP, San Pablo.

Eissa, S. (2017, 2 de agosto), "El sentido de las Fuerzas Armadas", en La Nación, Buenos Aires.

Eissa, S. (2013) "Redefiniendo la política de defensa: hacia un posicionamiento estratégico defensivo regional", Revista de la Sociedad Argentina de Análisis Político, Buenos Aires: Sociedad Argentina de Análisis Político, Vol. 7, № 1, , pp. 41-64.

Eissa, Sergio (2015), ¿'La irrelevancia de los Estados Unidos? La política de defensa argentina (1983-2010), Buenos Aires: Arte y Parte.

Fontana, A. (1998), “La seguridad internacional y la Argentina en los años 90", en Cisneros, A. (Comp.), Política exterior argentina (1989-1999). Historia de un éxito, Buenos Aires: Centro de Estudios de Política Exterior del Consejo Argentino de Relaciones Internacionales (CARI) y Grupo Editor Latinoamericano, pp. 275-341.

Fraga, R. (1989), La cuestión militar 1987-1989, Buenos Aires: Editorial del Centro de Estudios para la Nueva Mayoría.

Fraga, R. (1997), La cuestión militar al finalizar los 90, Buenos Aires: Editorial del Centro de Estudios para la Nueva Mayoría.

Fraga, R. (1998), “El concepto de las hipótesis de conflicto”, en Cisneros, Andrés (Comp.), Política exterior argentina 1989-1999. Historia de un éxito, Buenos Aires: Nuevo Hacer. Grupo Editor Latinoamericano, pp. 237-273.

Fraga, R. (2002), La política de defensa argentina. A través de los mensajes presidenciales al 
Congreso, Buenos Aires: Instituto de Historia Militar Argentina.

Frederic, S. (2013), Las trampas del pasado: las Fuerzas Armadas y su integración al Estado democrático en Argentina, Buenos Aires: Fondo de Cultura Económica.

Frederic, S.; Soprano, G.; Bracamonte, A.; Levoratti, A. y Martínez Acosta, M. (2010), “La formación militar como formación moral: transmisión y adquisición de sa-beres teóricos y prácticos en las Fuerzas Armadas", en Frederic, S.; Graciano, O. y Soprano, G. (Coords.), El Estado argentino y las profesiones liberales, académicas y armadas, Rosario: Prohistoria Ediciones, pp. 387-420.

Fundación Arturo Illia (1986), Publicaciones № 1, Buenos Aires: Fundación Arturo Illia para la Democracia y la Paz.

Fundación Arturo Illia (1988), Defensa y seguridad - Publicación № 5, 6 y 7, Buenos Aires: Fundación Arturo Illia para la Democracia y la Paz.

Gastaldi, S. (2012), El modelo de control civil informal en Bolivia durante la primera presidencia de Evo Morales (2006-2010). Divergencias con el modelo argentino de control civil institucionalizado (2003-2007). Tesis de Maestría, Escuela de Defensa Nacional, Buenos Aires.

Geddes, B. (1994), Politician's dilemma: Building state capacity in Latin America, Los Angeles: The University of California Press.

Haas, P. (1992), "Introduction: epistemic communities and international policy coordination", International Organization, Cambridge: Cambridge University Press, Vol 41, № 1, pp. 1-35.

Hirst, M. (1996), Democracia, seguridad e integración. América Latina en un mundo en transición, Buenos Aires: Norma.

Hirst, M. (2004), "La fragmentada agenda de la (in) seguridad regional”, en Hirst, M.; Russell, R.; Pérez Llana, C. y Tokatlián, J. (Eds.). Imperio, Estados e Instituciones. La política internacional en los comienzos del siglo XXI. Buenos Aires: Altamira y Fundación OSDE, pp. 99-146.

Huser, H. (2002), Argentine Civil-Military Relations. From Alfonsín to Menem, Washington DC: National Defense University Press.

Instituto de Defensa y Seguridad (2004), La política de defensa argentina en democracia (1983-2003), Buenos Aires: Nueva Mayoría Editorial.

López, E. (1994), Ni la ceniza ni la gloria. Actores, sistema político y cuestión militar en los años de Alfonsín, Quilmes: Universidad Nacional de Quilmes.

López, E. (2007), "Argentina: un largo camino hacia el control civil sobre los militares", en López, E. (Comp.), Control civil sobre los militares y política de defensa en Argentina, Brasil, Chile y Uruguay, Buenos Aires: Altamira, pp. 17-37.

Martínez, P. (2002), La reestructuración de las Fuerzas Armadas y el rol del Congreso. La experiencia argentina, La Paz: Centro de Estudios Hemisféricos de Defensa.

Martínez, P., "La reestructuración de las Fuerzas Armadas y el rol del parlamento: la experiencia argentina", Fuerzas Armadas y Sociedad (FASOC), Santiago de Chile: FLAC- 
SO, Año 15, № 1, enero-marzo, 2000, pp. 29-38.

Montenegro, G. (2003), “Nuevas Amenazas: aproximación desde una perspectiva internacional”, en López, E. y Sain, M. (Comps.), Nuevas Amenazas. Dimensiones y perspectivas. Dilemas y desafíos para la Argentina y Brasil. Quilmes: Universidad Nacional de Quilmes, pp. 85-114.

Montenegro, G. (2006, 5 de julio), Defensa: una política de consenso nacional, en La Nación, Buenos Aires.

Montenegro, G. (2013), “Más vale pájaro en mano que cien volando. La implementación del control político civil sobre las Fuerzas Armadas. La experiencia argentina 20052010. Entre la voluntad política y las limitaciones prácticas", en Pion-Berlin, D. \& Ugarte, J. (2013), Organización de la defensa y control civil de las Fuerzas Armadas en América Latina, Buenos Aires: Jorge Baudino Ediciones, pp. 195225.

Mora y Araujo, M. (2009), El problema argentino: débil representación política, sociedad fragmentada, Buenos Aires: IPSOS Mora y Araujo.

Orieta, R. (1985). Reforma militar para la defensa nacional. Buenos Aires: Ediciones Pequén.

Pesce, M.; Estevez, E.; Eissa, S. y Minteguiaga, A. (1999), El gasto en defensa del gobierno nacional, Buenos Aires: Fundación para el Estudio de los Temas Nacional Dr. Sergio Karakachoff - Cuaderno Cauce.

Pion-Berlin, D. (2005), "Political management of the military in Latin America", Military Review, Military Module. Fort Leavenworth, Vol. 85, № 1, pp. 19-31.

Poczynok, I., "Caminos cruzados. Un estado de la cuestión sobre las agendas política y académica de la defensa argentina (1983-2003)", Revista Militares e Politica, № 9, julio-diciembre, 2012. Disponible en http://www.lemp.historia.ufrj.br/revista/index.html.

Putnam, R., "Diplomacy and domestic politics", International Organization, Cambridge: Cambridge University Press, Vol. 42, № 3, Summer, 1988, pp. 353-386.

Repetto, Fabián (1998), "Una mirada institucional a las políticas sociales”, en Cavarozzi, Marcelo (comp.), Hacia una matriz de gobierno en América Latina, Buenos Aires: Universidad Nacional de San Martín/Banco Interamericano de Desarrollo, sin datos. Una versión anterior de este trabajo fue publicada como Repetto, Fabián, "Notas para el análisis de las políticas sociales: una propuesta desde el institucionalismo", en Perfiles Latinoamericanos, México: FLACSO,№ 12, juliodiciembre de 1998, pp. 53-84

Rosenau, J. (1966), "Pre-theories and theories of foreign policy", en Farrell, B. (ed.), Approaches in comparative and international politics, Evanston: Northwestern University Press, pp. 27-92.

Russell, R. (1990), "Política exterior y toma de decisiones en América Latina: aspectos comparativos y consideraciones teóricas", en Russell, R. (comp.), Política exterior y toma de decisiones en América Latina, Buenos Aires: Grupo Editor Latinoamericano, pp. 255-274. 
Russell, R. (1991), Variables internas y política exterior, mimeo, Buenos Aires.

Sabatier, P. (1993), "Policy change over a decade or more", en Sabatier, P. Jenkin-Smiths, H. (Ed.), Policy change and learning. An advocacy coalition approach, Boulder, Westview Press, pp. 13-39.

Sabatier, P. (2007), "The need for better theories", en Sabatier, P. (ed.), Theories of the policy process, Boulder: Westview Press, pp. 3-17.

Sain, M. (2003), “Nuevos horizontes, nuevos problemas. Las Fuerzas Armadas argentinas frente a las Nuevas Amenazas (1990-2001)", en López, E. y Sain, M. (Comps.), Nuevas Amenazas. Dimensiones y perspectivas. Dilemas y desafíos para la Argentina y Brasil, Quilmes: Universidad Nacional de Quilmes, pp. 173-220.

Sain, M. (2010), Los votos y las botas. Estudios sobre la defensa nacional y las relaciones civilmilitares en la democracia argentina, Buenos Aires: Prometeo.

Sain, M., "Las Fuerzas Armadas en la Argentina. Los dilemas de la reforma militar en una situación de crisis", Security and Defense Studies Review, Vol. 2, Winter, 2003, pp. 223-224.

Sain, M., "La defensa nacional y los asuntos militares en la Argentina actual”, Revista de la Defensa Nacional, Buenos Aires: Ministerio de Defensa, № 1, 2007, pp. 76-121.

Sain, M., "Quince años de legislación democrática sobre temas militares y de defensa (19831998)", Desarrollo Económico. Revista de Ciencias Sociales, Buenos Aires: IDES, Vol. 40, № 157, 2000, pp. 121-142.

Sain, M., "Vaivenes y eficacia de la política militar del primer gobierno de Carlos Menem (1989-1995)", Fuerzas Armadas y Sociedad (FASOC), Santiago de Chile: FLACSO, Año 12, № 2, abril-junio, 1997, pp. 13-23.

Scheetz, T. (1993), El marco teórico, político y económico para una reforma militar en la Argentina, Documentos de Trabajo $N^{\circ}$ 50, EURAL, Buenos Aires.

Scheetz, T. y Cáceres, G. (1995), Defensa no provocativa. Una propuesta de reforma militar para la Argentina, Buenos Aires: Editora Buenos Aires.

Scheetz, T., "Defensa no-provocativa en Argentina”, Fuerzas Armadas y Sociedad (FASOC), Santiago de Chile: FLACSO, Vol. IX, № 4, 1994, pp. 9-11.

Scheetz, T., "La necesaria reforma militar argentina", Nueva Sociedad, Santiago de Chile: Fundación Friedrich Ebert, № 138, 1995, pp. 132-141.

Scheetz, T., "Los costos económicos de la Defensa en la Argentina y Chile y el esbozo de una solución", Revista de Ciencias Sociales, Bernal: Universidad Nacional de Quilmes, $N^{\circ} 3,1995$, pp. 157-174.

Scheetz, T., Pfurr, A. \& Gratacos, M. (2015), Manual de teoría de la gestión económica de las Fuerzas Armadas. Una contribución a las bases conceptuales para la orientación de la política militar, Buenos Aires: Nuevo Hacer Grupo Editor Latinoamericano.

Soprano, G. \& Lafferriere, G. (2015), El Ejército y la política de defensa en la Argentina del Siglo $X X I$, Buenos Aires: Protohistoria. 
Soprano, G. (2016), ¿Qué hacer con las Fuerzas Armadas? Educación y profesión de los militares argentinos en el Siglo XXI, Buenos Aires: Prometeo.

Tamayo Saenz, M. (1997), “El Análisis de las Políticas Públicas”, en Bañón, R. y Carillo, E. (ed.), La Nueva Administración Pública, Madrid: Alianza, pp. 281-312

Tello, A. (2004), “Cooperación en la lucha antiterrorista”, en Stanganelli, I. (Comp.), Seguridad y Defensa en el Cono Sur, Buenos Aires: Caviar Blue. Editorial Andina Sur, pp. 29-40.

Tello, A. (2006), "La transición hacia la democracia en la Argentina. Reforma de las Fuerzas Armadas", en Huerta, J.; Tello, A. y otros (Comps.), Operaciones Conjuntas. Civiles y militares en la política de defensa, Lima: Instituto de Defensa Legal, pp. 3149.

Tello, A., "Conceptos de seguridad y defensa”, Relaciones Internacionales, La Plata: Instituto de Relaciones Internacionales de la Universidad Nacional de La Plata, Año 9, № 19, 2000, pp. 135-137.

Tello, A., "La inseguridad absoluta", Archivos del Presente, Buenos Aires: Fundación Foro del Sur, Año 7, № 25, 2001, pp. 23-26.

Tello, A., "La incertidumbre estratégica”, Escenarios Alternativos, Revista de Análisis Político, Buenos Aires: Fundación de Estudios para el Desarrollo Social, Año 3, № 7, 1999, pp. 121-126.

Tibiletti, L. y García, F., "Seguridad, Fuerzas Armadas y Narcotráfico. Una problemática de Estado", Paz y Seguridad en las Américas, Santiago de Chile: FLACSO, № 15, diciembre, 1997, pp. 39-45.

Tini, M., "Variables domésticas y política exterior: una ecuación indisociable. Los casos de Argentina y Paraguay", Polítikós, Santa Fe: Universidad Católica de Santa Fe, № 4, 2005, pp. 99-117.

Tokatlián, J. (2004, 13 de junio), El desacierto de enviar tropas a Haití, en Página /12, Buenos Aires.

Tokatlian, J. (2007, 19 de septiembre), ¿Para qué seguir en Haití?, en La Nación, Buenos Aires.

Tokatlian, J. (2015: 3 de septiembre), “Militares y narcotráfico: una combinación letal”, en Clarin, Buenos Aires.

Tokatlian, J. (2016, 19 de septiembre), "El país necesita una discusión sobre defensa", en La Nación, Buenos Aires.

Tokatlian, J. (2017, 14 de septiembre), “Militares y terrorismo: una (otra) mala combinación”, en Clarín, Buenos Aires.

Tomassini, L. (1989), Teoría y práctica de la política internacional, Santiago de Chile: Universidad Católica de Chile.

Ugarte, J. (1990), "La comisión de defensa nacional: un rol casi inédito”, en Druetta, G.; Estevez, E.; López, E. y Miguens, J. (1990), Defensa y democracia, Buenos Aires: Puntosur, pp. 245-251. 
Ugarte, J. (2003), Los conceptos jurídicos y políticos de la seguridad y la defensa: un análisis orientado a América Latina, Buenos Aires: Plus Ultra.

Ugarte, J. (2011), “La política de defensa argentina durante el 2010: consolidación del rumbo y problemas pendientes", en Mathieu, H. y Niño Guarnizo, C. (Ed.), Anuario 2011 de la seguridad regional en América Latina y el Caribe, Buenos Aires: Programa de Cooperación en Seguridad Regional - Friedrich Ebert Stiftung, pp. 11-19.

Van Klaveren, A. "Entendiendo las políticas exteriores latinoamericanas: modelo para armar", Estudios Internacionales, Santiago de Chile: Instituto de Estudios Internacionales de la Universidad de Chile, Año XXV, № 98, abril-junio, 1992, pp. 169-216.

Verbitsky, H. (1987). Civiles y militares: memoria secreta de la transición. Buenos Aires: Contrapunto.

Vigliero, S. (2002), Relaciones cívico-militares y política de defensa en Argentina, Disponible en www.resdal.org/archivo/d0000267.htm [Acceso: 20 de abril de 2008].

Vigliero, Sebastián (2004), Política de defensa y relaciones cívico-militares en Argentina: herramientas para la inserción del país en el mundo. Ponencia presentada en el VII Encuentro Nacional de Estudios Estratégicos “Defensa e Integración, Escuela de Defensa Nacional, Buenos Aires.

Vigliero, S. (2005), Política de defensa y relaciones cívico-militares en Argentina: herramientas para la inserción del país en el mundo, Disponible en www.flacso.org.ar. [Acceso: 20 de abril de 2008].

Von Clausewitz, C. (1976), De la guerra, Barcelona: Editorial Labor.

Von Clausewitz, C. (1999), De la guerra, Madrid: Ministerio de Defensa del Reino de España.

Zahariadis, N. (2003), Ambiguity \& Choice in public policy, Washington DC: Georgetown University Press.

Zahariadis, N. (2007), "The multiple stream framework: structure, limitations, prospects", en Sabatier, P. (Ed.), Theories of the policy process, Boulder: Westview Press, pp. 65-92. 